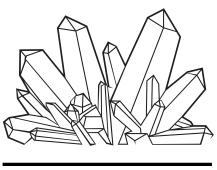

Электронная версия доступна на сайте www.fmm.ru/Новые данные о минералах

Минералогический музей

имени А.Е. Ферсмана РАН

Новые данные о минералах, том 55, вып. 1 (2021), 14-23

$\underline{\text { НДМ }}$

\title{
О деарсенизации сперрилита при прокалке шлихов
}

\author{
Л.А. Паутов ${ }^{1}$, М.А. Мираков², Ф.Ш. Искандаров ${ }^{3}$ \\ ${ }^{1}$ Минералогический музей им. А.Е. Ферсмана РАН, Москва, pla58@таil.ru \\ ${ }^{2}$ Институт геологии, сейсмостойкого строительства и сейсмологии НАН Таджикистана, Душанбе \\ ${ }^{3}$ Главное управление геологии при Правительстве Республики Таджикистан, Душанбе
}

В статье приведены результаты опытов по прокаливанию сперрилита в условиях, близких к условиям прокаливания богатых пиритом шлихов для перевода сульфидов в магнитные огарки и отделения их от минералов элементов платиновой группы (МПГ). При прокаливании в окислительных условиях смеси пирита со сперрилитом (фракция $-0.5-+0.1$ мм) при $420-450{ }^{\circ} \mathrm{C}$ за 1 час сперрилит по периферии зерен подвергается деарсенизации с образованием неполных псевдоморфоз платины по сперрилиту. Такие продукты прокаливания PtAs ${ }_{2}$ имеют структуру ореха: ядро - реликтовый сперрилит, кайма (мощностью до 100 мкм) - металлическая платина. Редко в кайме платины наблюдаются серповидные трещины разрыва. При прокаливании при $600{ }^{\circ} \mathrm{C}$ за 1.5 часа сперрилит вне зависимости, прокаливалась чистая фракция сперрилита или в смеси с пиритом, полностью переходит в металлическую платину. Деарсенизация сперрилита сопровождается образованием весьма характерных для этого процесса структур: возникновением зон с различной пористостью и образованием своеобразных серповидных трещин. На основании этих опытов делается вывод о том, что метод прокалки шлихов с целью отделения пирита от МПГ путем превращения сульфидов в магнитные огарки имеет серьезные ограничения. Достоинством этого метода является его простота, малое время, требующееся для сепарации материала и весьма высокий коэффициент обогащения, практически исключающий необнаружение сперрилита и других немагнитных МПГ, если они присутствовали в шлихе. Недостатком метода обжига шлихов является то, что сперрилит даже за относительно короткое время прокаливания (1 час) подвергается деарсенизации и, следовательно, метод применим для установления факта присутствия в шлихах сперрилита, но малопригоден для сепарации шлихов с целью выделения минералов благородных металлов для их более детального изучения.

Ключевые слова: сперрилит, платина, деарсенизация, минералы элементов платиновой группы, шлихи, прокаливание.

\section{Введение}

Для выделения и последующего изучения минералов элементов группы платины (МПГ) в россыпных месторождениях приходится обогащать пробы, так как обычно содержания МПГ слишком малы, чтобы работать непосредственно с необогащенным материалом. Первый этап концентрирования МПГ чаще всего проводят путем отмывки шлиха в лотках, ковшах, бутарах и других устройствах для промывания материала. Иногда используются отсадочные машины, циклоны или концентрационные столы. На этом первом этапе обогащения происходит значительное сокращение объема проб (часто сопровождающееся потерей части МПГ) и получается концентрат, содержащий еще значительное количество легкого материала (Кухаренко, 1961). Второй этап обогащения полученного концентрата обычно проводят уже в лабораторных условиях, и он может включать в себя дополнительную промывку (иногда вместо воды используют бромоформ) в лотках, чашках, стаканах и т.п. с несколькими этапами пе- 
речистки. Легкие минералы часто отделяют в тяжелых жидкостях, реже - в расплавленных тяжелых солях (Чуева, 1954; Кухаренко, 1961; Ложкин, 1962; Методы, 1985, и др.). Разделение в тяжелых жидкостях может дополняться или заменяться отдувкой (Ложкин, 1962; Методика, 1992). В зависимости от минералогического состава концентрата дальнейшее обогащение его иногда включает магнитный, электростатический и т.п. этапы сепарации (Методы, 1985).

Значительно осложняется выделение МПГ из шлихов и концентратов, в которых резко преобладают сульфиды, прежде всего пирит. Такая ситуация нередко возникает при обработке шлихов из элювиально-склоновых россыпей, источником которых являются коренные проявления неокисленных или малоокисленных сульфидных руд, а также при обработке искусственных шлихов и дробленых сульфидных руд. Дополнительные перечистки концентратов методом отмывки или отдувки нередко не дают должного результата. Широко распространенные тяжелые жидкости имеют слишком малую плотность (бромоформ - 2.89, жидкость Туле - 3.2, йодистый метилен 3.32, жидкость Рорбаха - 3.45, жидкость Клеричи

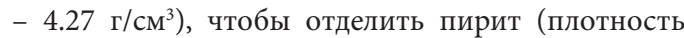

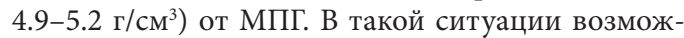
ны разные подходы к изучению МПГ в шлихах или протолочках: работа с материалом со слабой степенью обогащения или использование для сепарации более сложных способов обогащения. Первый подход - работа с необогащенным или малой степени обогащения материалом - весьма трудоемок. Некоторое облегчение при этом подходе приносят методы автоматического анализа изображений фракций в режиме BSE (по заданному порогу серого) и получение энергодисперсионных спектров с каждого пикселя, отвечающего пороговым условиям по среднему атомному номеру (Ford et al., 2011). Другой подход - применение более сложных методов сепарирования минералов. Для отделения пирита от МПГ по плотности можно использовать разделение в расплаве нитрата таллия и ртути с температурой плавления $77{ }^{\circ} \mathrm{C}$ и плотностью 5.3 г/см³ (Чуева, 1954; Ложкин, 1962), однако этот способ не получил широкого распространения, вероятно, из-за высокой стоимости и токсичности $\mathrm{HgTl}\left(\mathrm{NO}_{3}\right)_{2}$. Предложено для сепарации минералов применять бромид ртути $\mathrm{HgBr}_{2}$ (Grandstaff, 1972). Однако это соединение тоже имеет некоторые недостатки для сепарации минералов по плотности: при комнатной температуре это твердое кристаллическое вещество, и разделение минералов в нем предлагается проводить при температуре $250{ }^{\circ} \mathrm{C}$, когда $\mathrm{HgBr}_{2}$ превращается в почти непрозрачную жидкость с плотностью 5.08

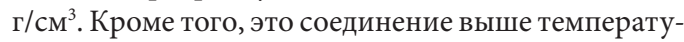

ры плавления $\left(236^{\circ} \mathrm{C}\right)$ обладает заметной летучестью и сильно ядовито. Для выделения немагнитных МПГ из проб с резким преобладанием пирита может применяться разделение минералов в искусственно утяжеленных парамагнитных жидкостях (насыщенный раствор хлористого марганца может быть утяжелен в неоднородном магнитном поле до плотности 7.5 г/ $\mathrm{cm}^{3}$, а хлористого диспрозия - до 19 г/см³) (Методы, 1985). Весьма эффективно выделение МПГ из проб в узких классах крупности с помощью гидросепараторов HS-02 и HS-11 (Rudashevsky et al., 2002; Рудашевский, Рудашевский, 2006; Рудашевский и др., 2018).

Все перечисленные подходы к сепарации проб с резким преобладанием пирита требуют применения малораспространенных реагентов или специального оборудования. По этой причине в ряде производственных геологических организаций для выделения МПГ используют более простые, в определенном смысле суррогатные методы разделения минералов (т.е. методы, которые могут приводить к частичному изменению минералогического состава проб). Весьма прост метод избирательного растворения сульфидов в азотной кислоте (для этого лучше всего постепенно высыпать пробу в горячую кислоту) или царской водке (при этом будут потеряны или изменены МПГ, растворимые в кислотах) (Шелер, Поуэлл, 1962). Еще проще реализуем метод выделения немагнитных МПГ (прежде всего платины и сперрилита) с помощью удаления магнитной сепарацией пирита после прокалки проб и превращения его в магнитные огарки. Практически этот способ осуществляется следующим способом: пробу помещают в фарфоровую чашку и прокаливают на электроплитке с открытой спиралью или в муфеле при слабом красном калении при доступе воздуха. Обжиг ведут до выгорания пирита, обычно около одного часа. После охлаждения материала огарки легко убираются ручным магнитом и остаются немагнитные МПГ и продукты их изменения. Окисление пирита начинается при $420-500{ }^{\circ} \mathrm{C}$ и в значительной степени зависит от характера доступа воздуха, влажности воздуха и еще в большей степени от размера зерен минерала. Температура воспламенения пирита, по одним данным, для фракции 0.1-0.15 мм составляет $422{ }^{\circ} \mathrm{C}$, для фракции 0.2-0.3 мм - $424{ }^{\circ} \mathrm{C}$ (Петухов и др., 2013), по другим данным, для фракции крупнее 0.2 мм $-472{ }^{\circ} \mathrm{C}$ (Гофман, 1948). Процесс обжига пирита протекает с образованием в качестве промежуточного продукта пирротина, который окисляется до магнетита и далее до гематита:

$$
\begin{gathered}
\mathrm{FeS}_{2}+\mathrm{O}_{2}=\mathrm{FeS}+\mathrm{SO}_{2} \\
3 \mathrm{FeS}+5 \mathrm{O}_{2}=\mathrm{Fe}_{3} \mathrm{O}_{4}+3 \mathrm{SO}_{2} \\
4 \mathrm{Fe}_{3} \mathrm{O}_{4}+\mathrm{O}_{2}=6 \mathrm{Fe}_{2} \mathrm{O}_{3}
\end{gathered}
$$


Процесс обжига сопровождается образованием на поверхности зерен пористых корочек, состоящих из оксидов железа, главным образом гематита $\mathrm{Fe}_{2} \mathrm{O}_{3}$. Характерно, что получаемый огарок обладает, как правило, ярко выраженными ферромагнитными свойствами. Это указывает на присутствие в нем, помимо основных компонентов $\left(\mathrm{FeS}_{2}, \mathrm{Fe}_{2} \mathrm{O}_{3}\right)$, некоторых количеств магнитных соединений железа - пирротина и магнетита (Петухов и др., 2013).

Поведение сперрилита PtAs, при обжиге в диапазоне температур от 420 до $600^{\circ} \mathrm{C}$ и относительно коротком времени термической обработки - 1-1.5 часа (условия, применяемые при обогащении проб описываемым способом) изучены недостаточно. То, что сперрилит разлагается при прокаливании, известно еще из первого описания минерала (Wells, 1889), в котором указывается, что сперрилит при медленном нагревании в открытой трубке легко дает сублиматы трехокиси мышьяка, при быстром нагревании - легко плавится. H.L. Wells (1889) пишет, что, пожалуй, наиболее характерная черта сперрилита следующая: при падении на раскаленную платиновую фольгу он мгновенно плавится, выделяет белые пары триоксида мышьяка, а на платине образуются пористые наросты, которые по цвету не отличаются от нетронутой фольги. Судя по приведенному описанию, трудно судить о температуре этих испытаний, но с большой вероятностью речь идет о температуре, значительно превышающей $600{ }^{\circ} \mathrm{C}$.

Интересная работа, имеющая отношение к данной теме, была проведена по изучению и интерпретации генезиса сферул Pt-PtAs, в большом количестве в ряде россыпей на севере Финляндии (Vuorelainen, Toernroos, 1986). Авторы этой работы пришли к выводу о техногенном происхождении этих сферул (50-200 мкм), сложенных эвтектоидного облика агрегатом платины и сперрилита. По данным ДТА у сперрилита наблюдается сильный экзотермический эффект в диапазоне $408-572{ }^{\circ} \mathrm{C}$, а в продукте после термического анализа (нагрев до $900{ }^{\circ} \mathrm{C}, \Delta \mathrm{T}=5$ \%мин) мышьяк ЭДС-анализом не обнаруживается, а фиксируется наличие только платины. Зерна после термического анализа не округлились и не приобрели структур эвтектоидного облика, характерных для сферул из россыпей. Однако прокаливание зерен сперрилита в смеси с влажным песком (температура обработки не приводится) привело к возникновению сфер, схожих с найденными на севере Финляндии. На основании этого авторы считают, что сферы Pt-PtAs, в россыпи имеют рукотворную природу и образовались в результате сушки шлихов с помощью паяльной лампы (Vuorelainen, Toernroos, 1986).

Деарсенизация сперрилита при прокалива- нии на воздухе, в вакууме и в атмосфере паров мышьяка изучалась Т.Л. Евстигнеевой с соавторами (1990). Отжиг сперрилита при $400{ }^{\circ} \mathrm{C}$ на воздухе в течение 10 суток привел к образованию на зернах сперрилита каймы платины толщиной 100-150 мкм, отжиг в течение 7 суток при $600{ }^{\circ} \mathrm{C}$ и 3 суток при $900{ }^{\circ} \mathrm{C}$ вызвал практически полную деарсенизацию сперрилита и превращение его в агрегат пористой платины.

Приведенные примеры изучения поведения при прокаливании сперрилита показывают, что его деарсенизация происходит при нагревании от $400{ }^{\circ} \mathrm{C}$ и выше. Однако либо температура опытов при прокаливании сперрилита не указывалась (Wells, 1889; Vuorelainen, Toernroos, 1986), либо длительность выдержки его при высокой температуре была более чем на порядок больше (от 3 до 10 суток) (Евстигнеева и др., 1990), чем продолжительность прокалки шлихов (1-1.5 часа) для превращения сопутствующего пирита в тяжелой фракции шлиха в магнитные огарки.

Для выяснения характера изменений сперрилита при прокаливании при условиях, применяемых при сепарации шлихов, были проведены простые опыты, результаты которых приводятся ниже. Опыты проводились при температуре $600 \pm 10^{\circ} \mathrm{C}$ и $420-450 \pm 5^{\circ} \mathrm{C}$. Выбор этих температур обусловлен следующими причинами: $600{ }^{\circ} \mathrm{C}$ - это, по нашим оценкам, наибольшая температура, которая может быть достигнута при прокаливании шлиха в фарфоровой чашке на электроплитке с открытой спиралью; $420-450{ }^{\circ} \mathrm{C}$ - минимальная температуpa, при которой пирит крупностью $-0.5-+0.1$ мм достаточно интенсивно превращается в магнитные огарки.

\section{Оборудование, материалы и условия проведе- ния опытов}

Для опытов по прокаливанию сперрилита использовались обломки (фракция $-0.5-+0.1$ мм) крупного зерна сперрилита с рудника Октябрьский Норильского рудного поля, любезно предоставленного Ю.Д. Гриценко. В опытах прокалки сперрилита в смеси с пиритом использовался пирит из буроугольного карьера Боровичи в Новгородской области. Прокаливание проводилось в муфельной $\left(600 \pm 10^{\circ} \mathrm{C}\right)$ и в трубчатой печи $(420-$ $\left.450 \pm 5{ }^{\circ} \mathrm{C}\right)$. Контроль и поддержание заданной температуры в муфельной печи осуществлялся с помощью платинародий-платиновой термопары $\mathrm{Pt}-\mathrm{PtRh}_{10}$ (ТПП). При прокаливании материала в трубчатой печи для большей надежности контроля за температурой к кварцевой пробирке (внутренним диаметром 5 мм) с пробой медной проволокой были прикреплены хромель-алюмелевая термопара (ТXА) (она же была датчиком для автоматического поддержания температуры) и ртут- 
ный термометр с диапазоном измеряемых температур от 0 до $500{ }^{\circ} \mathrm{C}$ и ценой делений $1^{\circ}$. Эта связка помещалась в кварцевую трубку диаметром 25 мм, а она уже вводилась в трубчатую печь (рис. 1).

После охлаждения проб магнитные продукты прокаливания пирита убирались ручным магнитом. Немагнитные зерна продуктов прокаливания сперрилита монтировались на предметных стеклах с помощью эпоксидной смолы Petropoxi-540. Полученные препараты шлифовались и полировались с помощью алмазных абразивов. Изучение продуктов прокаливания сперрилита в полированных препаратах проводилось в отраженном свете на поляризационном микроскопе Ortholux Leitz и во вторичных (SE) и обратно рассеянных электронах (BSE) на рентгеновском микроанализаторе JCXA Superprobe-733 JEOL. Элементный состав образцов определялся с помощью $\mathrm{Si}(\mathrm{Li})$ энергодисперсионного спектрометра и системы анализа INCA Energy-350 Oxford при ускоряющем напряжении 20 кВ и токе зонда 1 нА.

\section{Результаты отжига сперрилита на воздухе при}

\section{$600{ }^{\circ} \mathrm{C}$ в течение 1.5 часа}

Две порции зерен сперрилита (ориентировочно по 100 зерен) помещались в две фарфоровые чашки. В одной чашке зерна сперрилита засыпались зернами пирита (соотношение сперрилит:пирит около 1:1000). Обе чашки с пробами помещались в холодную муфельную печь, постепенно температура была доведена до $600^{\circ} \mathrm{C}$, и при этой температуре пробы выдерживались в печи 1.5 часа. Регулярно дверка печи приоткрывалась для свободного доступа воздуха к пробам. После охлаждения проб и удаления магнитных огарков из пробы с пиритом от обеих проб остались зерна серебристого цвета, внешне очень похожие на исходный сперрилит. При просмотре в отраженном свете препаратов из продуктов обжига сперрилита никакой разницы между материалом, который обжигался с пиритом и без пирита, отмечено не было. В отраженном свете видно, что отражательная способность фазы несколько изменчива, но стала значительно выше, чем у исходного сперрилита. В зернах наблюдается более низко отражающая кайма мощностью 10-30 мкм, а в крупных зернах имеются области с разноориентированными серповидными трещинами. В некоторых зернах имеются окаймляющие трещины (или зоны выкрашивания), повторяющие форму зерен на расстоянии 50-100 мкм от края зерна (рис. 2, 3a).

Близкая картина наблюдается при просмотре препаратов в режиме BSE (рис. 3, 4). Зерна оказались нацело сложены платиной. На уровне чувствительности ЭДС-анализа мышьяк не обнаруживается. Различия в тоне различных зон в зернах на изображениях в BSE и в отраженном свете связано с различной пористостью платины, а не с различиями в элементном составе.

\section{Результаты отжига сперрилита при $420-450{ }^{\circ} \mathrm{C}$ в течение 1 часа}

Смесь зерен сперрилита и пирита была прокалена при доступе воздуха в течение 1 часа при температуре $420-450 \pm 5^{\circ} \mathrm{C}$ в кварцевой пробирке, помещенной в открытую кварцевую трубу. На холодной поверхности кварцевой трубы, в которой находилась связка пробирки с материалом, термопары и термометра, во время прокаливания сконденсировались белые налеты триоксида мышьяка (рис. 1). После охлаждения пробы и отделения магнитных продуктов прокаливания пирита оста-

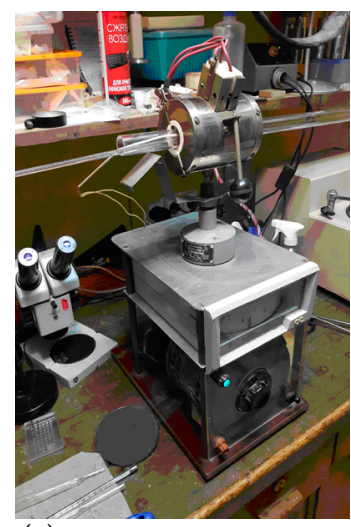

(a)

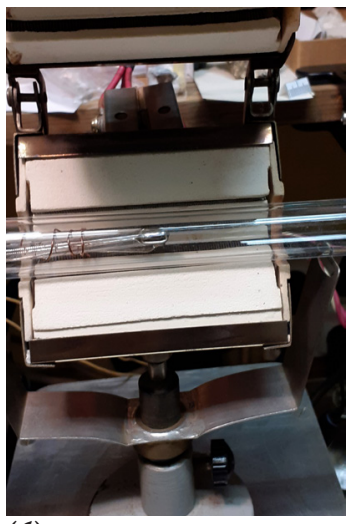

(6)

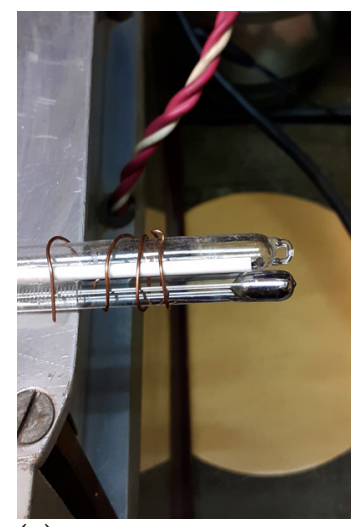

(B)

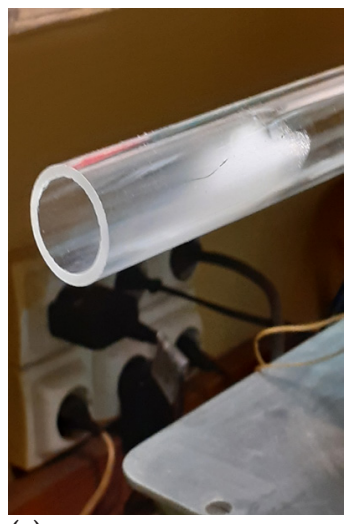

(г)

Рис. 1. Установка, в которой проведено прокаливание сперрилита при $420-450{ }^{\circ} \mathrm{C}$ : а - общий вид установки; 6 кварцевая трубка в печи, в которой помещена связка пробирки со сперрилитом, ХА-термопары и ртутного термометра; в - вид связки пробирки со сперрилитом, ХА-термопары и термометра; г - сублиматы оксидов мышьяка на внутренней поверхности кварцевой трубы, образовавшиеся в процессе прокалки сперрилита. 
вались серебристо-белые зерна, весьма схожие по внешнему виду с исходным сперрилитом. В отраженном свете и при наблюдении в режиме BSE (рис. 5-8) видно, что все зерна имеют центральную часть, представленную сперрилитом, и кайму (40-100 мкм толщиной), сложенную платиной. Граница между сперрилитом и платиной резкая волнистая. В некоторых зернах в кайме платины наблюдаются крупные трещины разрыва, близкие к тем, что наблюдались в зернах сперрилита, прокаленного при $600{ }^{\circ} \mathrm{C}$.

\section{Основные результаты и обсуждения}

Опыты по отжигу сперрилита при условиях (температура 420-600 ${ }^{\circ} \mathrm{C}$, выдержка 1-1.5 часа), близких к условиям прокаливания богатых пиритом шлихов для перевода сульфидов в магнитные огарки и отделения их от МПГ, показали:

- При $600{ }^{\circ} \mathrm{C}$ при доступе воздуха за 1.5 часа сперрилит (фракция $-0.5-+0.1$ мм) вне зависимости от того, прокаливалась ли чистая фракция сперрилита или в смеси с пиритом, полностью переходит в металлическую платину. Деарсенизация сперрилита сопровождается образованием весьма характерных для этого процесса структур: возникновением зон с различной пористостью и об-

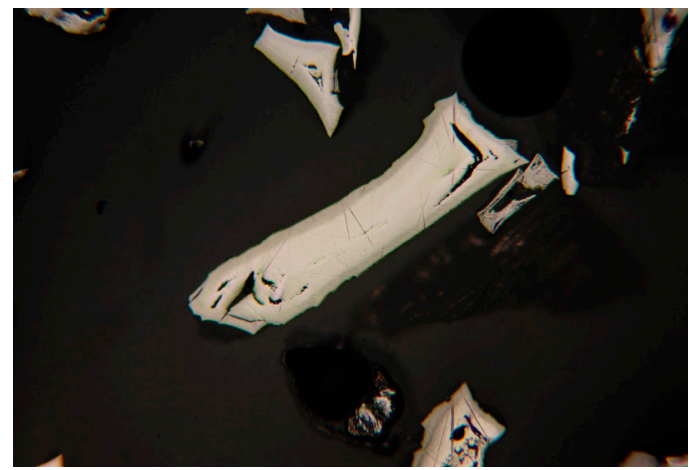

(a)

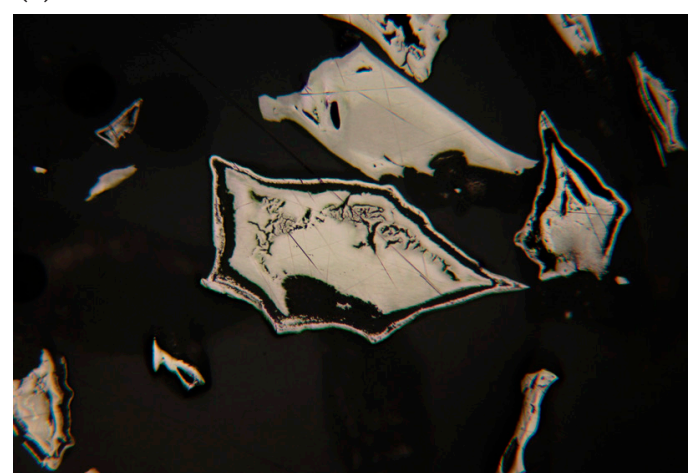

(B) разованием своеобразных серповидных трещин. Т.Л. Евстигнеева с соавторами (1990) объясняют возникновение пористости и трещин в платине тем, что при выходе атомов мышьяка из структуры сперрилита происходит сжатие элементарной ячейки и уменьшение объема, приходящегося на один атом: $14.93 \times 10^{-3} \mathrm{Hм}^{3}$ в Pt и $17.70 \times 10^{-3} \mathrm{Hм}^{3}$ в PtAs. $_{2}$.

- При прокаливании при 420-450 $\mathrm{C}$ при доступе воздуха уже за 1 час сперрилит (фракция $-0.5-+0.1$ мм) по периферии зерен подвергается деарсенизации с образованием неполных псевдоморфоз платины по сперрилиту. Такие продукты прокаливания $\mathrm{PtAs}_{2}$ имеют структуру ореха: ядро - реликтовый сперрилит, кайма (мощностью до 100 мкм) - металлическая платина. Редко в кайме платины наблюдаются серповидные трещины разрыва.

Из этих результатов можно сделать некоторые практические выводы о применимости метода выделения сперрилита из шлихов, богатых сульфидами, путем прокалки с последующим удалением магнитом образовавшихся магнитных огарков. Достоинством этого метода является его простота, малое время, требующееся для сепарации материала, и весьма высокий коэффициент обогащения,

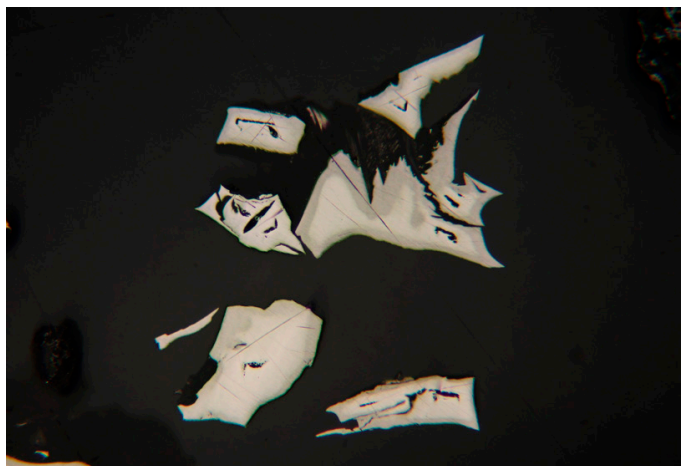

(б)

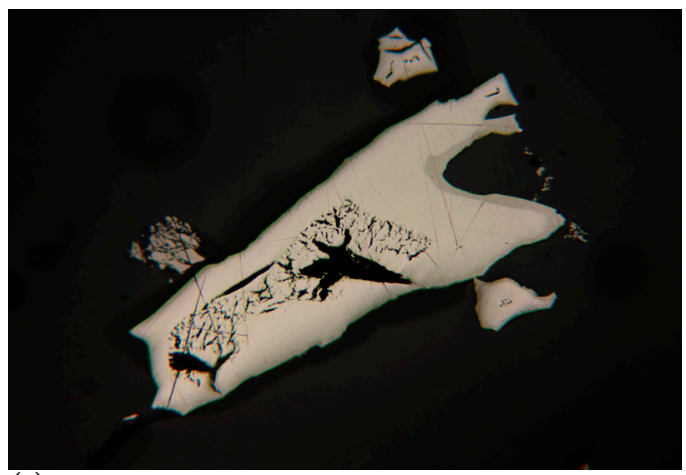

(г)

Рис. 2. Вид прокаленных при $600 \pm 10^{\circ} \mathrm{C}$ зерен сперрилита (превратившихся в платину) в отраженном свете при одном николе. Видны участки и зоны, отличающиеся отражательной способностью, и серповидные трещины. Ширина поля зрения 0.8 мм. 
практически исключающий необнаружение сперрилита и других немагнитных МПГ, если они присутствовали в шлихе. Прокаливание проб лучше вести при минимальной возможной температуре, обеспечивающей переход сульфидов в магнитные

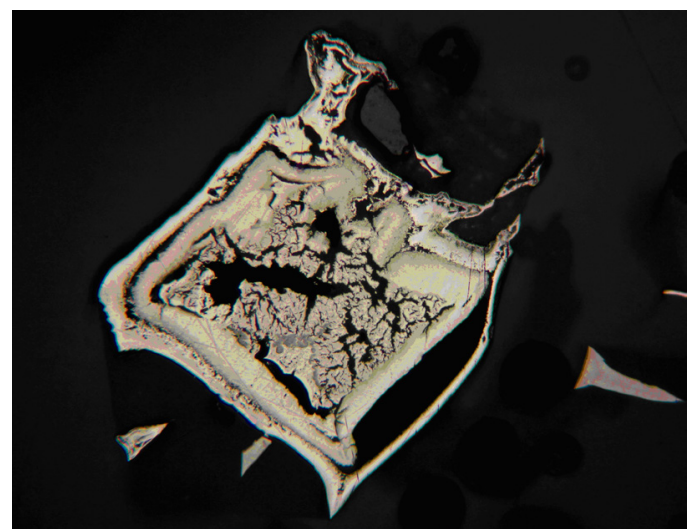

(a)

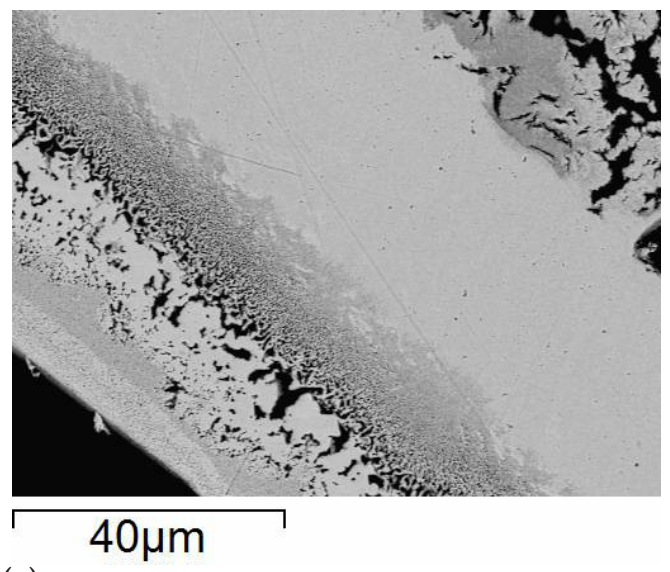

(B) огарки. Для фракции $-0.5-+0.1$ мм такой температурой является $420-450{ }^{\circ} \mathrm{C}$. Недостатком метода обжига является то, что сперрилит даже за относительно короткое время прокаливания (1 час), подвергается деарсенизации и, следовательно, метод

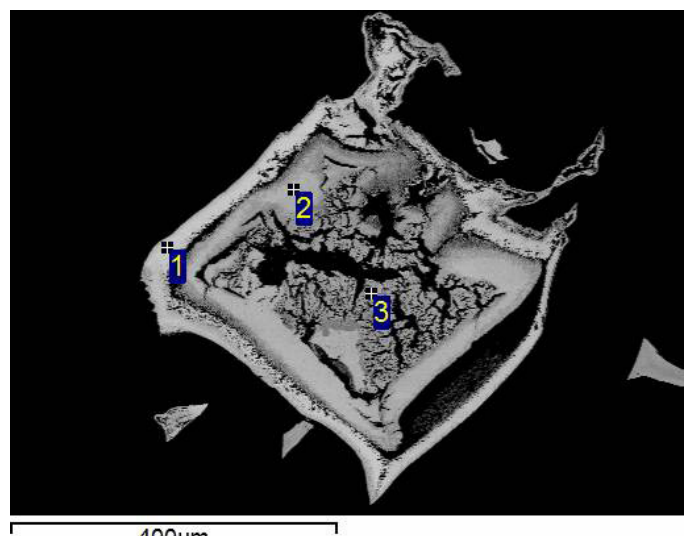

(б)

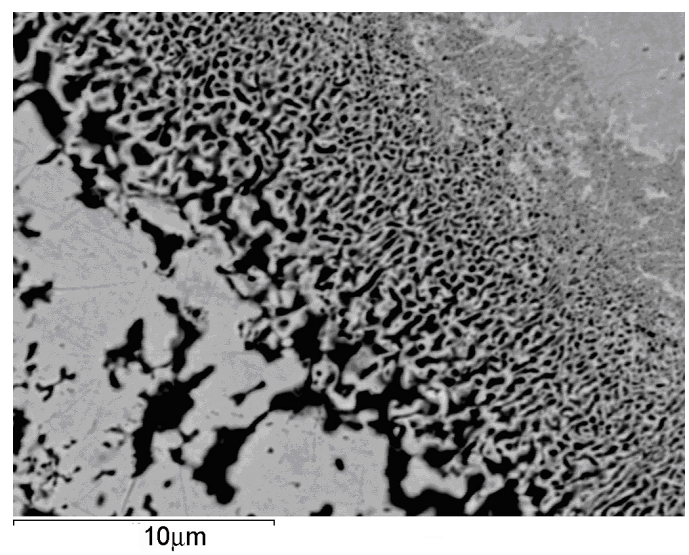

(г)

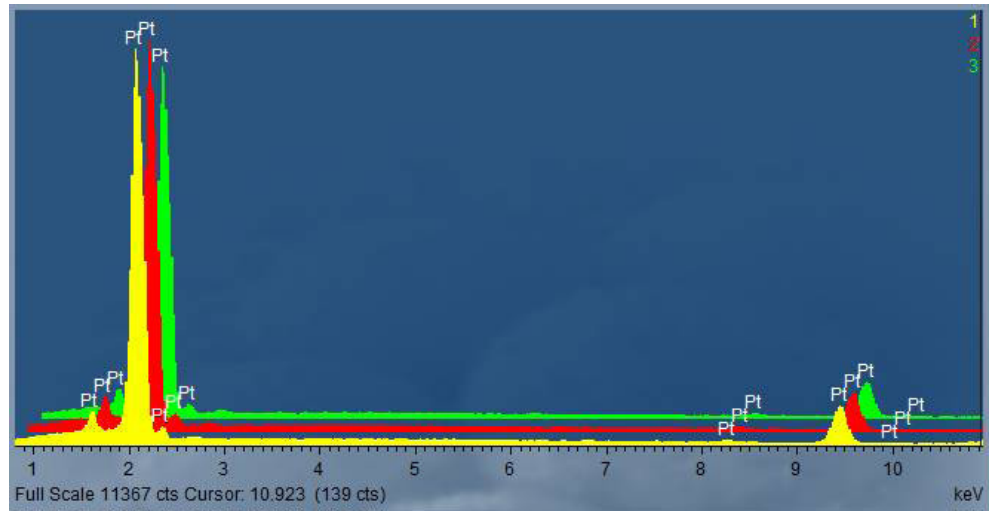

Рис. 3. Вид прокаленного при $600 \pm 10{ }^{\circ} \mathrm{C}$ зерна сперрилита (превратившегося в платину): а - в отраженном свете при одном николе, 6 - тот же участок при наблюдении в режиме BSE; в - фрагмент предыдущего снимка. Видно, что зоны, отличающиеся по тону на изображении при малом увеличении, представлены участками с различным размером и формой пор; г - фрагмент снимка 3в; д - сравнение энергодисперсионных спектров с разных участков (области анализа отмечены на рис. 36). Видно, что эти участки анализов представлены платиной. Мышьяк на уровне чувствительности ЭДС-анализа не обнаруживается. 
применим для установления факта присутствия в шлихах сперрилита (и других немагнитных МПГ), но малопригоден для сепарации шлихов с целью выделения для более полного изучения минералов благородных металлов.

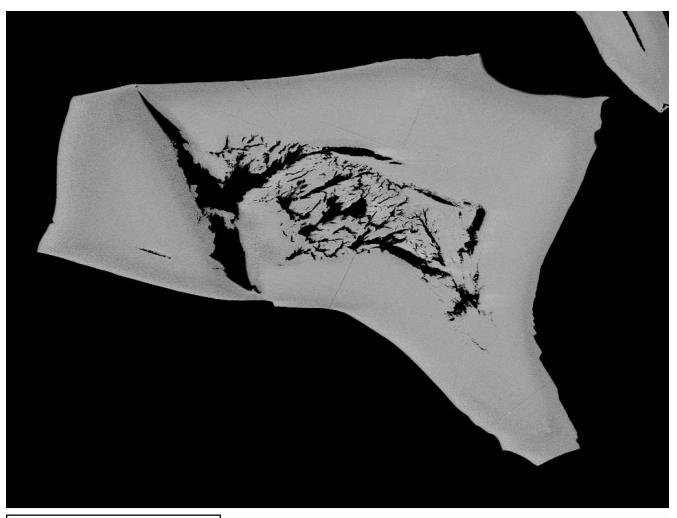

$100 \mu \mathrm{m}$

(a)

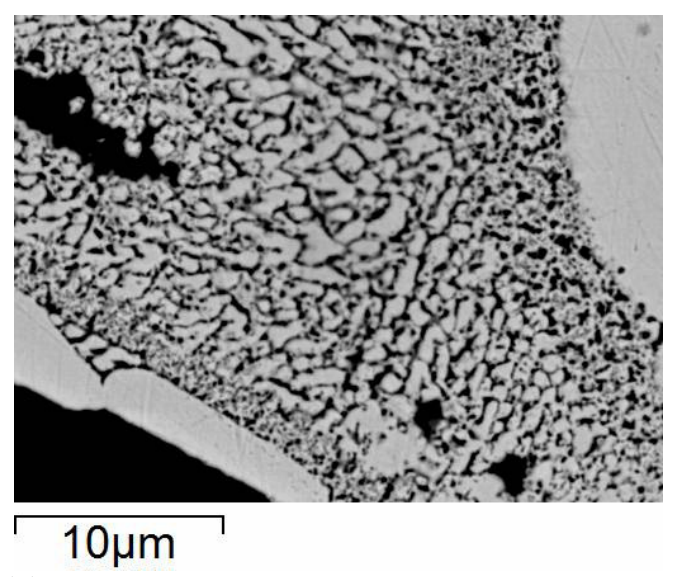

(B)

\section{Благодарности}

Авторы благодарят за предоставленный для опытов сперрилит Ю.Д. Гриценко и за обсуждение и советы Э.М. Спиридонова, А.О. Карпова.

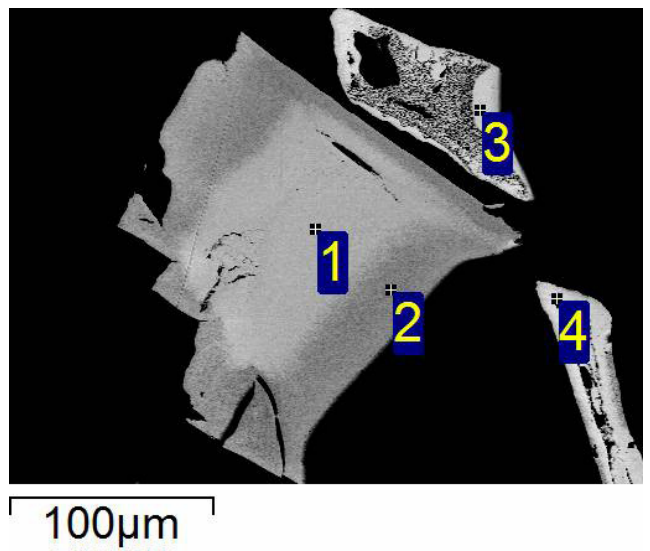

(б)

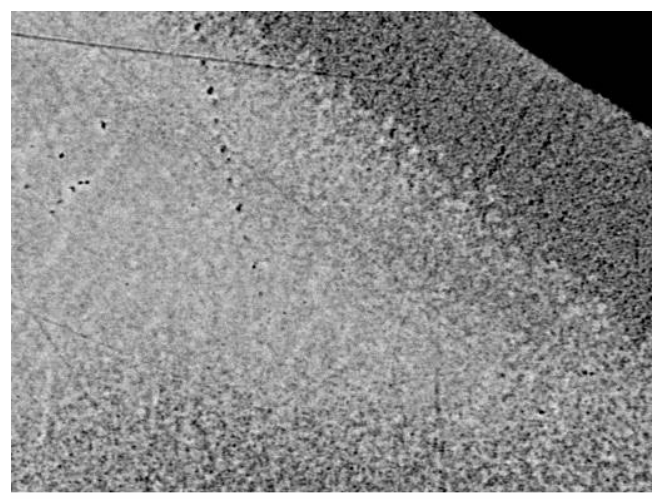

$10 \mu \mathrm{m}$

(г)

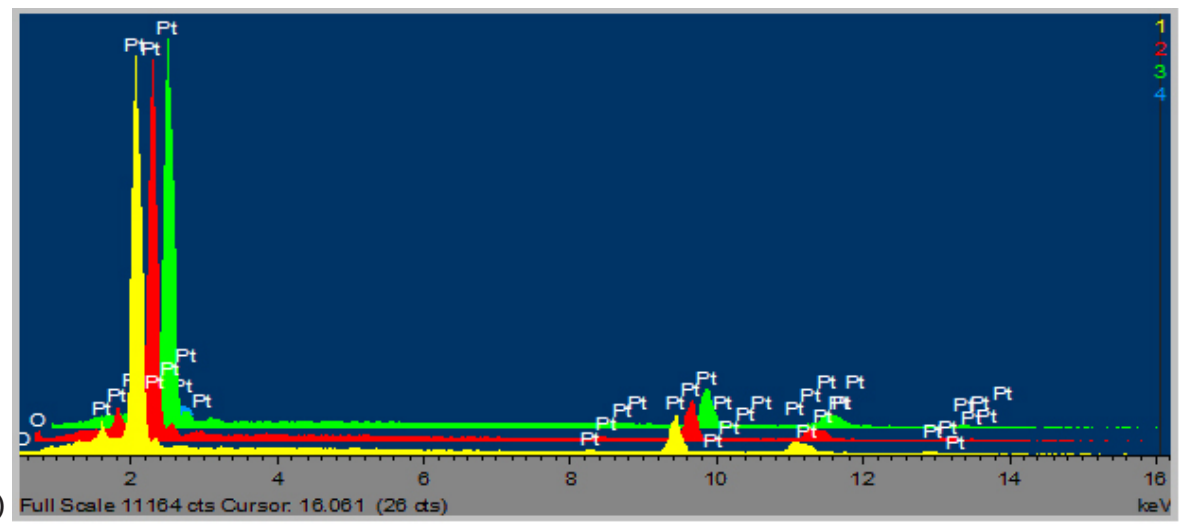

Рис. 4. Вид зерен сперрилита, прокаленных при $600 \pm 10{ }^{\circ} \mathrm{C}$, в режиме BSE. а - в центральной части зерна видны крупные серповидные и сложной морфологии трещины разрыва; 6 - зерна с помеченными участками ЭДС-анализа; в - фрагмент предыдущего снимка (верхнее зерно); г - фрагмент при большем увеличении верхней правой части зерна (крупного зерна на рис. 46); д - сравнение энергодисперсионных спектров с разных участков (области анализа отмечены на рис. 46). 


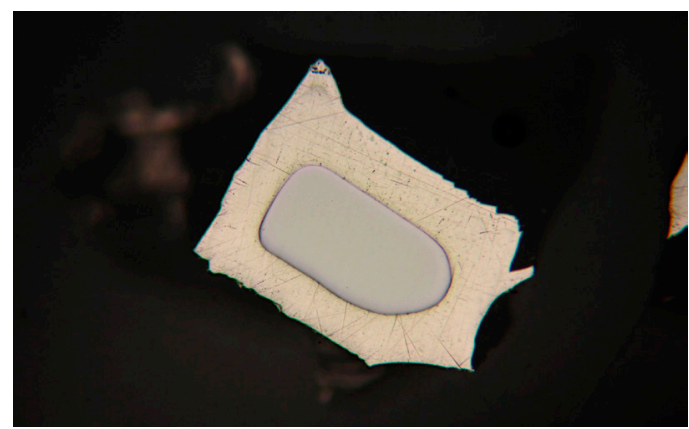

(a)

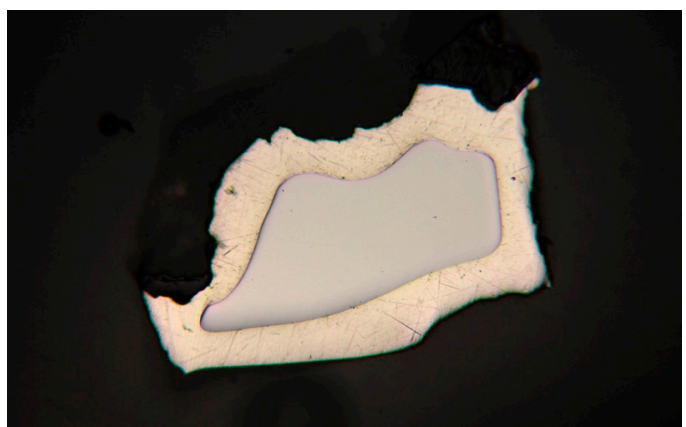

(б)

Рис. 5. Вид продуктов прокаливания сперрилита при $420-450^{\circ} \mathrm{C}$ в отраженном свете при одном николе. Центральная часть зерен (серая) - сперрилит, более светлая кайма - платина. Ширина поля зрения 1 мм.

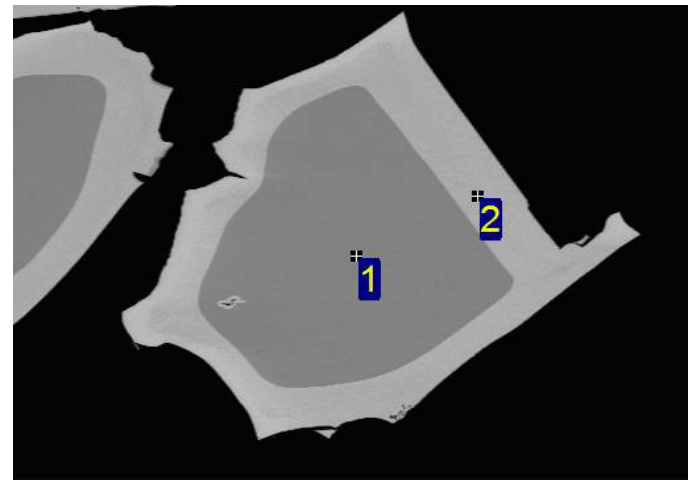

(a) $400 \mu \mathrm{m}$

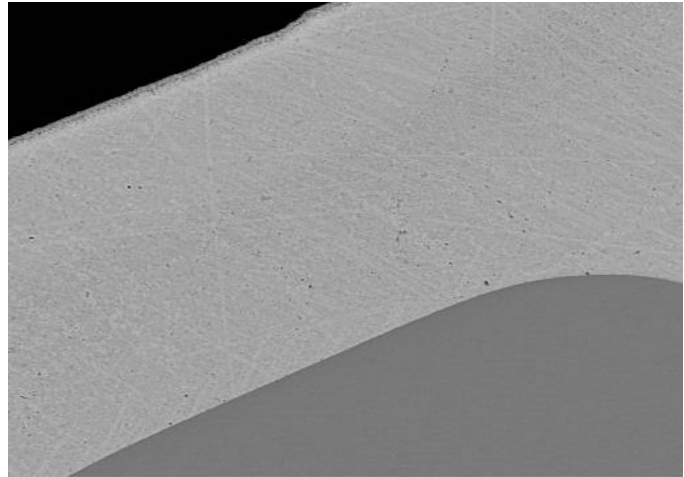

(б) $40 \mu \mathrm{m}$

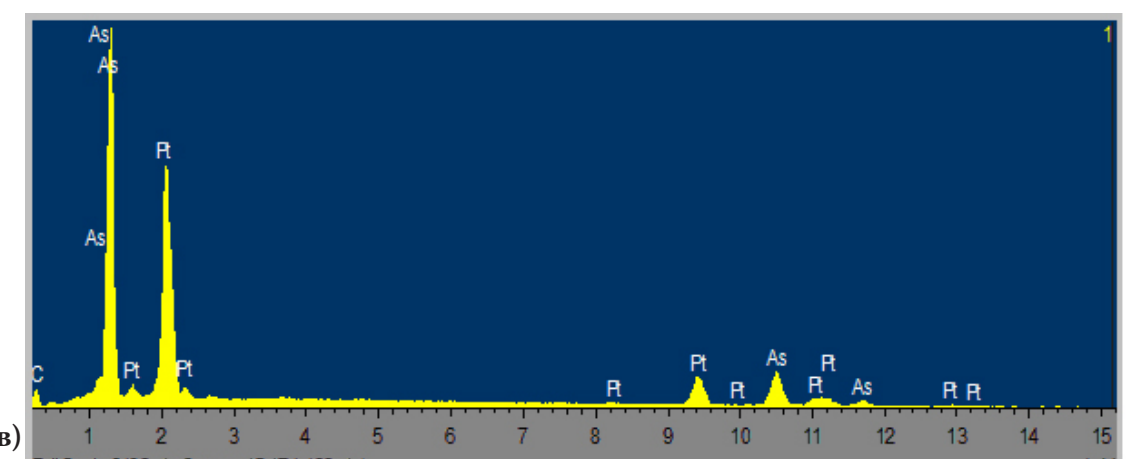

(в)

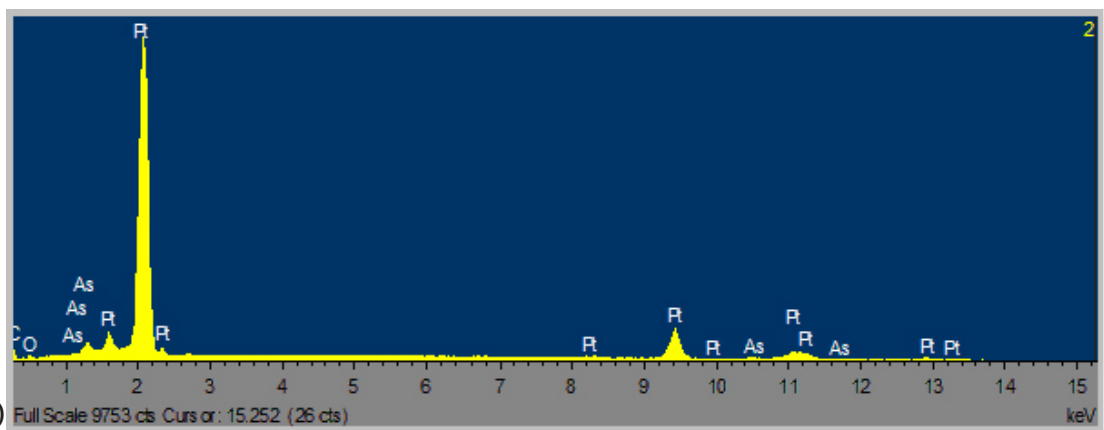

Рис. 6. Продукт прокаливания сперрилита при $420-450{ }^{\circ} \mathrm{C}$. а - вид зерна сперрилита (1) с каймой платины (2) в режиме BSE; 6 - фрагмент предыдущего снимка при большем увеличении, видна резкая граница между сперрилитом и платиной; в - ЭДС-спектр сперрилита (участок анализа 1 на рис. 6а); г - ЭДС-спектр платины (участок анализа 2 на рис. 6а). 


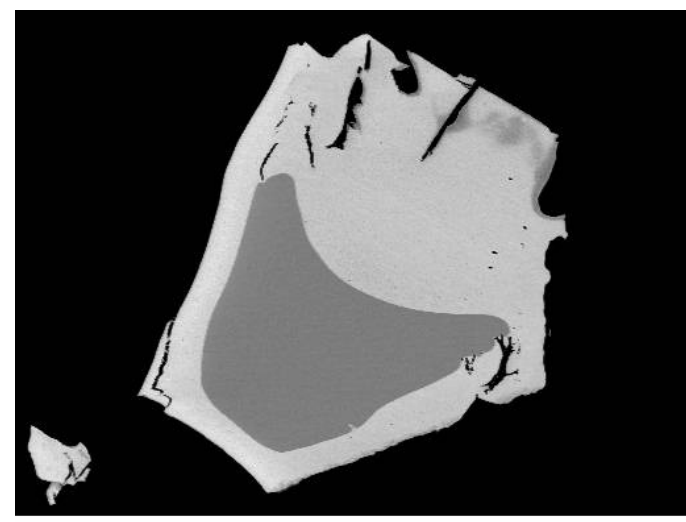

$500 \mu \mathrm{m}$

(a)

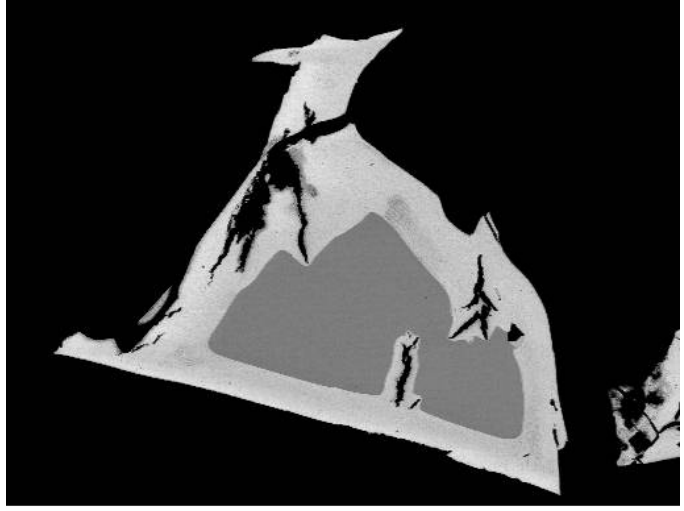

$300 \mu \mathrm{m}$

(б)

Рис. 7. Продукт прокаливания сперрилита при $420-450$ 으. Центральная часть зерен (серое) - сперрилит, кайма (светло-серое) - платина. В кайме платины видны трещины разрыва. Изображение в режиме BSE.

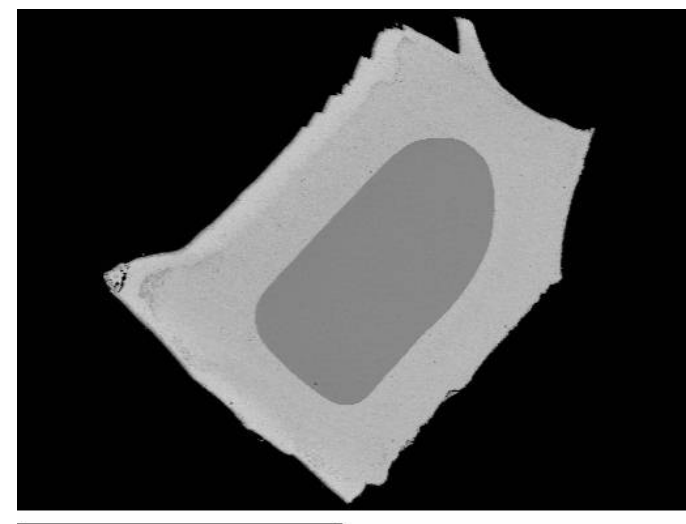

$300 \mu \mathrm{m}$

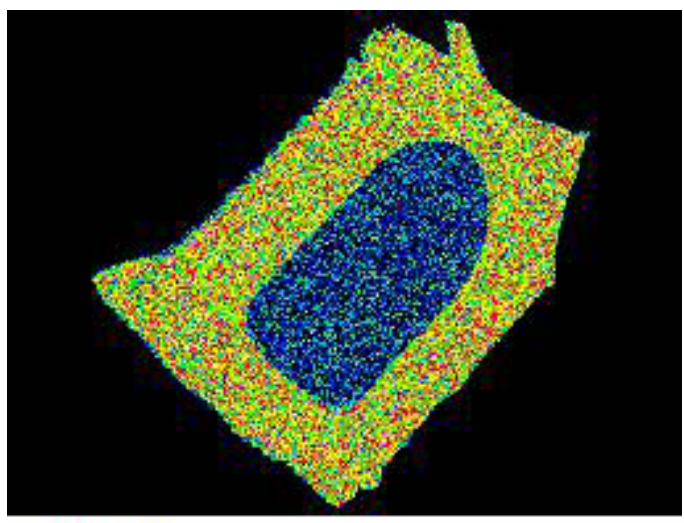

Pt Ma1

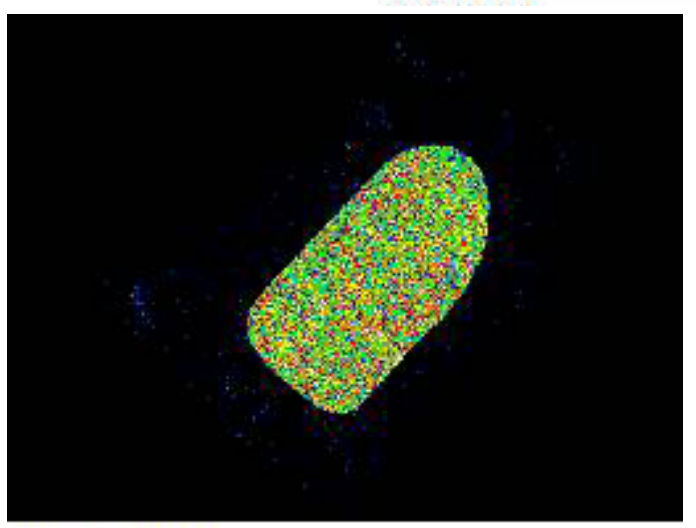

\section{As La1_2}

Рис. 8. Продукт прокаливания сперрилита при $420-450$ ㄷ․ Изображение в режиме BSE и рентгеновские карты распределения указанных элементов. 


\section{Список литературы:}

Гофман И.П. Физико-химические основы металлургии. М. 1948. 281 с.

Евстигнеева Т.Л., Ким А.А., Некрасов И.Я. О деарсенизации сперрилита в природе // Минерал. журнал. 1990. T. 12. № 3. С. 90.

Кухаренко А.А. Минералогия россыпей. М. 1961. $318 \mathrm{c}$.

Ложкин В.В. Диагностика минералов россыпей (практическое руководство). М. 1962. 244 с.

Методы минералогических исследований: Справочник / Под ред. А.И. Гинзбурга. М.: Недра, 1985. 480 с.

Методика разведки россыпей золота и платиноидов. Под ред. И.Б. Флерова, В.И. Куторгина. М.: ЦНИГРИ, 1992.307 c.

Петухов О.Ф., Санакулов К., Хасанов А.С., Мустакимов О.М. Окислительно-восстановительные процессы в металлургии. Ташкент: Истиклол нури, 2013. 279 с.

Рудашевский Н.С., Рудашевский В.Н. Гидравлический классификатор. Патент на изобретение № 2281808. Российская Федерация. 2006.

Рудашевский Н.С., Рудашевский В.Н., Антонов А.В. Универсальная минералогическая технология исследования пород, руд и технологических продуктов // Региональная геология и металлогения. 2018. № 73. С. 88-102.

Чуева М.Н. Практическое руководство по разделению минералов в тяжелых жидкостях и солях. М. 1954. 55 с.

Шелер В.Р., Поуэлл А.Р. Анализ минералов и руд редких элементов. М. 1962. 448 с.

Ford F.D., Wercholaz C.R., Lee A. Predicting process outcomes for Sudbury platinum-group minerals using grade-recovery modeling from mineral liberation analyzer (MLA) data // Canadian Mineralogist. 2011. V. 49. № 6. P. 1627-1642.

Grandstaff D.E. Use of Mercuric Bromide as a Heavy Liquid // American Mineralogist. 1972. V. 57. № 11/12. P. 18991902.

Rudashevsky N.S., Garuti G., Andersen J.Ø., Kretser Y.L., Rudashevsky V.N., Zaccarini F. Separation of accessory minerals from rocks and ores by hydroseparation (HS) technology: method and application to CHR-2 chromitite, Niquelândia intrusion, Brazil // Applied Earth Science. 2002. 111 (1). P. 87-94.

Vuorelainen Y., Toernroos R. Man-made Pt-PtAs spherules after sperrylite from alluvial deposits in Finnish Lapland // Canadian Mineralogist. 1986. V. 24. № 3. P. 523528.

Wells H.L. Sperrylite, a new mineral // American Journal of Science. 1889. V. 37 (137). № 217-222. P. 67-70. 